\title{
Satellite InSAR monitoring in tunnelling projects
}

chiara Giannico (TRE ALTAMIRA), Iolanda lannicella* (TRE ALTAMIRA), Giovanni Barla (Politecnico di Torino), Sara Del Conte (TRE ALTAMIRA)

\section{Summary}

Satellite radar interferometry (InSAR) has become an operational tool for monitoring tunnelling projects and other engineering works in urban areas. The technique is a remote sensing approach for measuring ground displacement from satellite radar images and has applications in all phases of tunnelling projects, including planning, construction and operation/maintenance.

In this study, we describe a recent case study where InSAR was applied during the construction of a twin tunnel in Sicily, Italy, where significant ground surface settlement occurred during TBM excavation. 


\section{Main Objectives:}

The main objectives of this study are:

- Present satellite InSAR technology as an operational tool for monitoring tunnelling works during all phases of the project (i.e. design, construction, operation), in both urban and nonurban areas.

- Report a recent case study where InSAR was applied during the construction of a twin tunnel in Sicily, Italy, where significant ground surface settlement occurred during TBM excavation.

\section{New Aspect Covered}

Correlation between horizontal displacements ("extrusions"), measured underground ahead of the tunnel face during excavation, and the resulting surface settlements measured by satellite radar data.

\section{Summary}

Satellite radar interferometry (InSAR) has become an operational tool for monitoring tunnelling projects and other engineering works in urban areas. The technique is a remote sensing approach for measuring ground displacement from satellite radar images and has applications in all phases of tunnelling projects, including planning, construction and operation/maintenance.

Urban contexts are particularly sensitive to risks and constraints associated with tunnelling activities due to the high density of risk-prone elements and for obvious requirements imposed by public safety. InSAR has unique characteristics for complementing in situ observations, significantly improving the quality of the monitoring solution. Key features are:

- No need to install anything on ground. By exploiting as "natural targets" elements quite common in urban areas (e.g. metallic objects, poles, walls facing toward the radar), a high density of measurement points can be obtained, complementing traditional ground-based surveys;

- InSAR data can provide baseline studies, highlighting possible ground deformation phenomena affecting the area of interest, ante operam, i.e. before construction. In fact, it is possible to take advantage of historical satellite data acquired over most of the urban areas over the last few years;

- InSAR can provide a synoptic view over an area much wider than the one monitored with in situ instrumentations and allows one to detect and monitor (although with a temporal frequency of a few days, not suitable for real-time applications) "far-field" and residual deformation following tunneling activities.

In this study, we describe a recent study showing an advanced application of InSAR during the TBM excavation of the 4-km long "Caltanissetta" twin tunnel, in Italy. The tunnel, with a $15.08 \mathrm{~m}$ diameter for each tube, was excavated in difficult ground, under a maximum cover of $130 \mathrm{~m}$. Significant ground surface settlement occurred during excavation, affecting a sensitive inhabited area. InSAR analysis, as well as conventional topographic surveys, were adopted as monitoring tools and results were compared. In addition, a special monitoring section of the tunnel was instrumented with a horizontal inclinometer installed across it. The aim was to monitor the induced horizontal displacements ("extrusions"), as the tunnel face was approaching it and compare them with surface settlements. To this purpose, a three-dimensional finite difference model was implemented, in order to back analyse the monitoring results and provide useful hints about the observed response in the tunnel and at the ground surface

Authors: Sara Del Conte, Giovanni Barla, Chiara Giannico, Iolanda Iannicella 